\title{
Multi-Criteria Wind Turbine Selection using Weighted Sum Approach
}

\author{
Shafiqur Rehman \\ Center for Engineering Research \\ King Fahd University of Petroleum \& Minerals \\ Dhahran, Saudi Arabia
}

\author{
Salman A. Khan \\ Computer Engineering Department \\ University of Bahrain \\ Sakhir, Bahrain
}

\begin{abstract}
Wind energy is becoming a potential source for renewable and clean energy. An important factor that contributes to efficient generation of wind power is the use of appropriate wind turbine. However, the task of selecting an appropriate, site-specific turbine is a complex problem. The complexity is due to the presence of several conflicting decision criteria in the decision process. Therefore, a decision is sought such that best tradeoff is achieved between the selection criteria. With the inherent complexities encompassing the decisionmaking process, this study develops a multi-criteria decision model for turbine selection based on the concepts of weighted sum approach. Results indicate that the proposed methodology for finding the most suitable turbine from a pool of 18 turbines is effective.
\end{abstract}

Keywords-Wind turbine; renewable energy; weighted sum method; multi-criteria decision-making

\section{INTRODUCTION}

The exponential growth in population, materialistic life styles, and fast industrialization has resulted in higher demand for energy. However, the awareness and sensitivity of deteriorating environmental changes have prompted the use of renewable and cleaner sources of energy to safeguard the life of our very planet. In recent years, substantial research has been devoted to develop systems and techniques that would enhance utilization of renewable energy sources. Such sources primarily include wind, solar, geothermal, and hydro, among others. Of these energy sources, wind power technology has emerged as a promising commercial alternative to the fossil fuel based energy [1]-[3]. The advantages of wind energy in comparison with traditional methods of power generation (e.g. coal, gas, or nuclear plants, etc.) lie in fast deployment and commissioning of wind farms. This is attributed to wind turbines which require minimal operation and maintenance attention and cost. In addition, the operational age of turbines lasts between 20 and 25 years which are quite cost effective. Furthermore, wind power harnessing is not restricted by geographical boundaries [4], [5], a case which is not prevalent with the fossil fuel based energy generation systems.

A recent report by Global Wind Energy Council [6] indicates that substantial progress has been made by several countries with regard to exploitation of wind energy. The statistics suggest that at the end of 2016, the global generation of wind energy reached 486,600 MW. This denotes an increase of around $2700 \%$ compared to that of year 2000 . Just in a period of one year from 2015 to 2016, the cumulative wind power generation increased by $12.5 \%$ from $432,680 \mathrm{MW}$ in 2015 to 486,749 MW. China currently leads the global market with addition of 23,328 MW of wind power to its national grid in 2016. Other prominent followers are USA, Germany, India, and Brazil adding 8,203, 5,443, 3,612 and 2,014 MW respectively in year 2016. Other countries such as France, Turkey, the Netherlands, UK and Canada are also catching up with the wind power generation. However, Africa and the Middle East are lagging behind, though some initiatives have recently been taken in some regions [6].

A fundamental challenge in harnessing wind energy is the maximization of energy output from turbines. It is a challenge since fluctuations arising in the speed of wind have a negative impact on energy generation [7]. The speed of wind depends heavily on geographical location, climatic conditions, topography, and height above ground level (AGL). In a typical setup, speed of wind is measured between 8 to 12 meters AGL. The tower height at which the turbine rotor is mounted is referred to as hub height. Since more wind is absorbed at higher hub heights, generally high hub heights are desired in a typical wind farm layout setting. However, the maximum hub height has a threshold due to installation, technical, maintenance, and economic issues. Another factor that affects the generation of energy is rotor diameter. While a bigger rotor diameter is associated with higher energy generation, rotor with smaller diameter is desired again due to cost and maintenance issues.

In addition to hub height and rotor diameter, the factors of cut-in wind speed and rated wind speed also have impact on energy output of a turbine. Cut-in wind speed refers to minimum wind speed at which the turbine starts functioning, while rated wind speed is referred to as the wind speed at which the turbine produces its maximum rated energy. It is desirable to have low values of cut-in wind speed and rated wind speed so that the turbine can operate in low windy sites. However, turbines with bigger rotor diameter are considered appropriate since they have large swept area, which in turn generates more power. In addition, turbines with higher rated capacity (the maximum power that can be generated by a turbine) require bigger rotor diameter. Thus, there is a need for a decision approach in order to find an optimal tradeoff between all the factors (a.k.a. decision criteria).

The rest of this paper is organized as: A review of relevant literature is given in Section 2. Novelty of the proposed work is discussed in Section 3. The research method 
is presented in Section 4. The discussion as how goal programming is applied to the problem considered herein is given in Section 5. Section 6 provides the results and discussion. Finally, a conclusion is given in Section 7.

\section{LITERATURE REVIEW}

Significant attention has been given to wind turbine selection problem in during the past two decades. A qualitative approach was adopted by Sarja and Halonen [8] who interviewed domain experts. Their research identified various turbine selection criteria such as product reliability and availability, production frequency of the vendor, cost, and maintenance patterns. Perkin et al. [9] utilized a genetic algorithm to find the most suitable turbine while employing various selection criteria such as rotor radius, generator size, hub height, and pitch angle. Nemes and Munteanu [10] proposed a system reliability based model to compare nine different turbine types. A particle swarm optimization based algorithm was proposed by Chowdhury et al. [11] for turbine selection. They considered a single turbine type while employing energy production capacity as the selection criterion. Firuzabad and Dobakhshari [12] used turbine reliability as the decision criterion in a probabilistic model that they developed. The proposed approach was tested on five turbine types. Bencherif et al. [13] developed a Weibull distribution based analytical approach and considered 24 different turbines models while using capacity factor as the decision criterion. Montoya et al. [14] proposed a Paretoranking based genetic algorithm to choose the best turbine. Their decision model considered power output and deviation in daily power output as the selection criteria. In an approach proposed by Chowdhury [15], more than 120 turbine types were considered while using cost of energy as the turbine selection criterion. Martin [16] assumed a hypothetical wind turbine to optimize the rotor-to-generator ratio and developed a simple support tool considering numerous wind conditions. Bekele and Ramayya [17] considered a site-specific turbine selection with blade design as the decision criterion. They proposed a genetic algorithm to optimize their model. Helgason [18] conducted a study on several potential sites in Iceland. For selection of turbines, cost of energy was used as the decision criterion and 47 different turbine models were considered. A genetic algorithm was proposed by Eke and Onyewudiala [19] for site-specific turbine selection. The aim was to maximize power generation while blade thickness, twist, and cord were used in the optimization model. A genetic algorithm was also employed by Jureczko et al. [20] for turbine design with the consideration of give design objectives. These objectives were generated output, blade structure stability, blade vibrations, blade material cost, and blade strength requirements.

Aljowder [21] proposed a turbine selection methodology using six different turbine models and used capacity factor as the decision criterion. El-Shimy [22] proposed a site-specific turbine selection methodology while considering average power output, capacity factor, and turbine performance index as the decision variables. Dong et al. [23] considered turbine selection while considering turbine cost and integrated matching indices as the optimization criteria. The proposed model was applied to genetic algorithm, differential evolution, and particle swarm optimization. An analytic hierarchy process (AHP) based approach [24] was proposed by Shirgholami et al. [25] who identified over 30 decision criteria, but only a subset of these criteria could be used in the selection process depending on the site-specific conditions. Bagocius et al. [26] proposed a weighted sum based approach for turbine selection for offshore wind farms. They considered five decision factors which were yearly energy generation, maximum power generated in the area, nominal power of the wind turbine, investments, and $\mathrm{CO}_{2}$ emissions. Lee et al. [27] proposed a multi-criteria decision approach while considering economic issues, environmental aspects, technical challenges, and machine characteristics as the major decision criteria. Four turbines, with all having almost the same rated power, were considered. Du et al. [28] proposed a turbine selection approach based on SCADA data analysis.

A turbine selection approach was proposed by Khan and Rehman [29], [30] who used fuzzy logic based multi-criteria decision approach considering three criteria. Subsequently, a fuzzy logic based turbine selection strategy consisting of six criteria was also proposed by them [31]. However, one limitation of these studies was the use of fuzzy decision making in which selection of an appropriate fuzzy operator is a challenge. It is due to the fact that different fuzzy operators may result in different decisions. This issue is overcome in the current study through the use weighted sum approach which does not suffer from such issues.

\section{NOVELTY OF THE PROPOSED WORK}

The review of studies in Section 2 points towards several limitations of the research as far as wind turbine selection is concerned. A number of studies [10]-[18], [21] assumed a simple decision model where a single criterion was considered in the decision process, and therefore lacks a realistic scenario where multiple factors affect the decision process. Another limitation of the studies was in terms of use of computationally expensive methods. Numerous studies used genetic algorithms, differential evolution, particle swarm optimization, and nonlinear programming [15]-[24], [26], [27]. Despite the fact that these approaches generally provide efficient solutions, they are computationally expensive. Another limitation observed in various studies [4], [16]-[21], [23], [24], [26], [27], [29], [30] was the use of limited number of turbines and/or lack of consideration of variety of turbines. This aspect limits the comprehensiveness of the concerned studies. One more issue that prevails in the existing studies is the use of decision factors for which information is not easily accessible (e.g. production volume, system reliability indices, maintenance schedules, blade shape, product reliability, visual impact, and political stability, among many others) [8]-[12], [16]-[24], [26]. Use of such parameters make the turbine selection process a complex one, and in many cases, impractical. Finally, one key limitation of those reported studies which assumed multi-criteria decision-making was that they did not focus on the fundamental requirement of conflict and incommensurability among the decision-criteria [8], [9], [14], [18]-[20], [22]-[24], [27]. Conflict refers to the situation where improvement in one (or more) criterion (criteria) has a negative impact on the other 
criteria. Incommensurability issues arise when decision criteria are of different magnitudes and units.

With the aforementioned observations, our proposed turbine selection approach, which is based on the weighted sum method [32], has several novel aspects and addresses the concerns present in the above studies. The proposed approach develops a turbine selection model considering five simple, yet important decision criteria, while taking into account the issues of conflict and incommensurability. These criteria are easily and readily available for any commercially available turbine, thus simplifying the proposed approach. Unlike many previous studies which used complex and time-inefficient techniques, the weighted sum method is simple and provides solutions in linear time, making the proposed approach computationally efficient. In addition, 18 turbines from a variety of manufacturers have been considered, thus enhancing the comprehensiveness of results. It is also important to mention that the proposed scheme is also scalable and robust; criteria as well as the types of turbines can be added or deleted easily according to the requirements of the designer, without affecting the computational efficiency.

\section{RESEARCH METHOD}

The research is based on an empirical study and uses five important decision criteria as identified from the literature survey. The decision criteria are hub height, rated speed of wind, cut-in speed of wind, rotor diameter, and turbine rated output. These criteria are used to develop the desired decision model based on the weighted sum method. First, using the data, the upper limit for each criterion is determined. Then, a normalized value of each criterion with respect to its corresponding upper limit is calculated. Finally, all normalized values are added together using the weighted sum approach (explained in next section). The minimum value of weighted sum is then taken as the best solution found.

\section{APPLICATION OF WEIGHTED SUM METHOD TO WIND TURBINE SELECTION}

Multi-criteria decision-making (MCDM) is substantially employed to tackle decision problems in which multiple and conflicting decision criteria are considered in the decision process. Several approaches, such as weighted sum method, goal programming, compromise programming, and fuzzy logic have been proposed in literature to solve MCDM problems. Weighted sum method has been widely used by researchers due to its simple approach and time efficiency [33]. To apply weighted sum approach to MCDM problems, a fundamental requirement is to aggregate criteria such that an overall decision function is formed (represented as a scalar value). However, this process highlights the need to overcome incommensurability of criteria, due to which different criteria cannot be combined into a single decision function. Therefore it is necessary to convert all criteria to a unit-less, uniform scale. This is done by normalizing each criterion such that the value of the criterion lie in a $0-1$ range. Then, weights are assigned to each normalized criterion according to the desire of the decision maker. Finally, all weighted values of criteria are added. Mathematically, the aim is to maximize (in case of a maximization problem) or minimize (in case of a minimization problem) the following equation:

$$
\sum_{\mathrm{i}=1}^{\mathrm{K}} \mathrm{W}_{\mathrm{i}} \mathrm{f}_{\mathrm{i}}(\mathrm{x})
$$

Where, $K$ represents the number of decision criteria and $\mathrm{w}_{\mathrm{i}}$ represents the weight of the $i^{\text {th }}$ criterion. Furthermore, $\mathrm{w}_{\mathrm{i}} \geq 0$ for all $i=1, \ldots . K$. In addition, the sum of all weights should be equal to 1 , that is, $\sum_{\mathrm{i}=1}^{\mathrm{K}} \mathrm{W}_{\mathrm{i}}=1$.

In order to apply the weighted sum approach using the five decision criteria, the upper limit for each criterion is required for the purpose of normalization of criteria. Note that we are dealing with a minimization problem. That is, our interest is finding the turbines that have minimum values of hub height, rotor diameter, cut-in speed of wind, and rated speed-of wind. However, the criterion of turbine rated power requires maximization. Therefore, the inverse of this criterion is taken such that the criterion is also considered for minimization. The normalized criteria are weighted and added. The resulting equation, as given below, is then used for the decision.

$$
\begin{gathered}
W_{1\left(\frac{\text { hub height }}{\text { max hub height }}\right)+} w_{2}\left(\frac{\text { rotor diameter }}{\text { maxrotor diamter }}\right)+w_{3}\left(\frac{\text { cut }- \text { in speed }}{\text { max cut-in speed }}\right)+ \\
W_{4\left(\frac{\text { rated speed }}{\text { maxrated speed }}\right)+} w_{5\left[1-\left(\frac{\text { rated power }}{\text { max rated power }}\right)\right]}
\end{gathered}
$$

Since equal preference is given to each criterion, and there are five criteria, all weights were assigned the same value of 0.2 . Furthermore, normalization was done using the upper limits given in the last row of Table 1. These limits were determined using the maximum value of each criterion given in the $2^{\text {nd }}$ last row of Table 1 .

\section{RESULTS AND DISCUSSION}

A C++ based program was developed to perform the simulations. The simulator performs the multi-criteria decisionmaking calculations using the input data and the weighted sum model of (2) to generate the decision output. Eighteen different turbine models with different rated powers and manufacturers were considered. Technical data of these turbines is given in Table 1.

Table 2 shows the individual normalized values for each criterion, along with the weighted sum value (calculated using (2)) in the last column of the table. It is observed from this table that Fuhrlander FL 600 has the minimum weighted sum of 0.575 , indicating that this is the best turbine among all turbines. The table also indicates that a potential alternative to Fuhrlander FL 600 is Ecotecnia 80/200 with a weighted sum of 0.578 . Note that Fuhrlander FL 600 has a rated capacity of 600 KW while Ecotecnia 80/200 has a rated power of $2000 \mathrm{KW}$. Therefore, the designer has a choice between turbines of high and low values of rated power. Furthermore, Suzlon S.52/600 is the worst turbine with the highest weighted sum of 0.706 . 
TABLE. I. TECHNICAL SPECIFICATIONS OF TURBINES [31]

\begin{tabular}{|l|l|l|l|l|l|}
\hline Turbine & $\begin{array}{l}\text { Minimum } \\
\text { Hub } \\
\text { Height }(\mathbf{m})\end{array}$ & $\begin{array}{l}\text { Rotor } \\
\text { Diameter } \\
(\mathbf{m})\end{array}$ & $\begin{array}{l}\text { Cut-in Speed of } \\
\text { wind }(\mathbf{m} / \mathbf{s})\end{array}$ & $\begin{array}{l}\text { Rated } \\
\text { Speed of } \\
\text { wind }(\mathbf{m} / \mathbf{s})\end{array}$ & $\begin{array}{l}\text { Rated } \\
\text { Power } \\
(\mathbf{K W})\end{array}$ \\
\hline Fuhrlander FL 600 & 50 & 50 & 2.5 & 11 & 600 \\
\hline Hyosung HS50 & 50 & 50 & 3.5 & 11 & 750 \\
\hline RRB Energy PS 600 & 48 & 47 & 3.5 & 15 & 600 \\
\hline Suzlon S.52/600 & 75 & 52 & 4 & 13 & 600 \\
\hline Unison U57 & 68 & 57 & 3 & 10.5 & 750 \\
\hline Vestas V47 & 55 & 47 & 4 & 13 & 660 \\
\hline Windflow 500 & 29 & 33 & 6 & 14 & 500 \\
\hline AAER A-1000 & 70 & 58 & 4 & 12 & 1000 \\
\hline DeWind D6 64m & 60 & 64 & 2.5 & 12.3 & 1250 \\
\hline Mitsubishi MWT62 & 69 & 61.4 & 3.5 & 12.5 & 1000 \\
\hline Nordex N54/1000 & 60 & 54 & 3.75 & 14 & 1000 \\
\hline Suzlon S.62/1000 & 65 & 62 & 3 & 12 & 1000 \\
\hline Vensys 62-1200 & 69 & 62 & 2.5 & 11.5 & 1200 \\
\hline AAER A-2000-84 & 65 & 84 & 3.25 & 12 & 2000 \\
\hline DeWind D8.1 & 80 & 80 & 3 & 13.5 & 2000 \\
\hline Ecotecnia 80/2000 & 70 & 80 & 3 & 12 & 2000 \\
\hline REpower MM92 & 79 & 92 & 3 & 12.5 & 2000 \\
\hline Suzlon S.88/2000 & 80 & 88 & 4 & 14 & 2000 \\
\hline Maximum & $\mathbf{8 0}$ & $\mathbf{9 2}$ & $\mathbf{6}$ & $\mathbf{1 5}$ & $\mathbf{2 0 0 0}$ \\
\hline Upper limit & $\mathbf{8 5}$ & $\mathbf{9 5}$ & $\mathbf{7}$ & $\mathbf{1 6}$ & $\mathbf{2 1 0 0}$ \\
\hline
\end{tabular}

TABLE. II. COMPARISON OF TURBINES USING THE WEIGHTED SUM

\begin{tabular}{|l|l|l|l|l|l|l|}
\hline Turbine & $\begin{array}{l}\text { Normalized } \\
\text { Hub Height }\end{array}$ & $\begin{array}{l}\text { Normalized } \\
\text { Rotor } \\
\text { Diameter }\end{array}$ & $\begin{array}{l}\text { Normalized } \\
\text { Cut-in Speed } \\
\text { of wind }\end{array}$ & $\begin{array}{l}\text { Normalized } \\
\text { Rated Speed } \\
\text { of wind }\end{array}$ & $\begin{array}{l}\text { Normalized } \\
\text { Rated Power }\end{array}$ & $\begin{array}{l}\text { Weighted } \\
\text { Sum }\end{array}$ \\
\hline Fuhrlander FL 600 & 0.588 & 0.526 & 0.357 & 0.688 & 0.714 & 0.575 \\
\hline Hyosung HS50 & 0.588 & 0.526 & 0.500 & 0.688 & 0.643 & 0.589 \\
\hline RRB Energy PS 600 & 0.565 & 0.495 & 0.500 & 0.938 & 0.714 & 0.642 \\
\hline Suzlon S.52/600 & 0.882 & 0.547 & 0.571 & 0.813 & 0.714 & 0.706 \\
\hline Unison U57 & 0.800 & 0.600 & 0.429 & 0.656 & 0.643 & 0.626 \\
\hline Vestas V47 & 0.647 & 0.495 & 0.571 & 0.813 & 0.686 & 0.642 \\
\hline Windflow 500 & 0.341 & 0.347 & 0.857 & 0.875 & 0.762 & 0.637 \\
\hline AAER A-1000 & 0.824 & 0.611 & 0.571 & 0.750 & 0.524 & 0.656 \\
\hline DeWind D6 64m & 0.706 & 0.674 & 0.357 & 0.769 & 0.405 & 0.582 \\
\hline Mitsubishi MWT62 & 0.812 & 0.646 & 0.500 & 0.781 & 0.524 & 0.653 \\
\hline Nordex N54/1000 & 0.706 & 0.568 & 0.536 & 0.875 & 0.524 & 0.642 \\
\hline Suzlon S.62/1000 & 0.765 & 0.653 & 0.429 & 0.750 & 0.524 & 0.624 \\
\hline Vensys 62-1200 & 0.812 & 0.653 & 0.357 & 0.719 & 0.429 \\
\hline AAER A-2000-84 & 0.765 & 0.884 & 0.464 & 0.750 & 0.048 & 0.594 \\
\hline DeWind D8.1 & 0.941 & 0.842 & 0.429 & 0.844 & 0.048 \\
\hline Ecotecnia 80/2000 & 0.824 & 0.842 & 0.429 & 0.750 & 0.048 \\
\hline REpower MM92 & 0.929 & 0.968 & 0.429 & 0.781 & 0.048 & 0.621 \\
\hline Suzlon S.88/2000 & 0.941 & 0.926 & 0.571 & 0.875 & 0.048 & 0.578 \\
\hline
\end{tabular}

\section{CONCLUSION}

An essential requirement for an efficient wind farm design is the selection of most suitable turbines such that maximum power can be harnessed with minimal effort and cost. However, selection of a suitable wind turbine from a pool of off-the-shelf available turbines is not an easy task since the decision-making process is governed by many criteria. Among several decision criteria, five important criteria are hub height, turbine rotor diameter, cut-in and rated wind speeds of a turbine, and turbine rated output. This study proposed a multicriteria decision-making approach for the turbine selection problem using the weighted sum approach. The proposed approach was motivated by the inherent limitations of previous studies. These limitations were due to simple decision models using a single criterion, use of computationally complex techniques, lack of variety of turbines, and complex decision criteria. The effectiveness of the proposed strategy was analyzed with its application to a number of wind turbine types from several manufacturers. Results indicate that Fuhrlander FL 600 was the best turbine, followed by Ecotecnia 80/200.

As a future work, we intend to perform an analysis of effects of weights assigned to different criteria as mentioned in the context of (2). Furthermore, we also intend to perform a comparative analysis of our weighted sum approach with other techniques such as goal programming and fuzzy logic. 


\section{ACKNOWLEDGMENTS}

The support of Deanship of Research at King Fahd University of Petroleum \& Minerals, Saudi Arabia, is acknowledged under project number IN 141039.

\section{REFERENCES}

[1] S. Rehman, M. Baseer, J. Meyer, M. Alam, M. Alhems, A. Lashin, and N. AlArifi, "Suitability of utilizing small horizontal axis wind turbines for off grid loads in Eastern Region of Saudi Arabia". Energ. Explor. Exploit., vol. 34, no. 3, pp. 449-467, March 2016.

[2] M. Baseer, J. Meyer, S. Rehman, M. Alam, M. L. Al-Hadhrami, and A. Lashin, "Performance evaluation of cup-anemometers and wind speed characteristics analysis". Renew. Energ., vol. 86, pp. 733-744, Feb. 2016.

[3] M. Baseer, J. Meyer, M. Alam, and S. Rehman, "Wind speed and power characteristics for Jubail industrial city, Saudi Arabia", Renew. Sust. Energ. Rev., vol. 52, pp. 1193-1204, December 2015.

[4] S. Khan, "An automated decision-making approach for assortment of wind turbines - a case study of turbines in the range of $500 \mathrm{~kW}$ to 750 kW". Int. J. Comput. Netw. Tech. 2015, vol. 3, no. 2, pp. 75-81, May 2015 .

[5] S. Rehman, and N. Al-Abbadi, "Wind power characteristics on the north west coast of Saudi Arabia" Energ. Env., vol. 20, no. 8, pp. 1257-1270, December 2009.

[6] Global Wind Statistics, GWEC 2016, http://www.gwec.net/wpcontent/uploads/2017/02/1_Global-Installed-Wind-Power-CapacityMW-\%E2\%80\%93-Regional-Distribution.jpg (Accessed on 28 February 2017)

[7] S. Khan, and S. Rehman, "Iterative non-deterministic algorithms in onshore wind farm design: A brief survey". Renew. Sust. Energ. Rev., vol. 19, pp. 370-384, March 2013.

[8] J. Sarja, and V. Halonen, "Wind turbine selection criteria: a customer perspective", J. Energ. Power. Eng., vol. 7, pp. 1795-1802, September 2013.

[9] S. Perkin, D. Garrett, D, and P. Jensson, "Optimal wind turbine selection methodology: A case-study for Búrfell, Iceland", Renew. Energ., vol. 75, pp. 165-172, March 2015.

[10] C. Nemes, and F. Munteanu, "Optimal selection of wind turbine for a specific area". In Proceedings of the IEEE 12th International Conference on Optimization of Electrical and Electronic Equipment, Brasov, Romania, pp. 1224-1229, May 2010.

[11] S. Chowdhury, J. Zhang, A. Messac, and L. Castillo, L, "Optimizing the arrangement and the selection of turbines for wind farms subject to varying wind conditions". Renew. Energ., vol. 52, pp. 273-282, April 2013.

[12] M. Firuzabad, and A. Dobakhshari. "Reliability-based selection of wind turbines for large-scale wind farms", Int. J. Electr. Electron Eng., vol. 3, no. 2, pp. 114-120, February 2009.

[13] M. Bencherif, B. Brahmi, and A. Chikhaoui, "Optimum selection of wind turbines", Sci. J. Energ. Eng., vol. 2, no. 4, pp. 36-46, August 2014.

[14] F. Montoya, F. Manzano-Agugliaro, S López-Márquez, Q. HernándezEscobedo, and C. Gil, "Wind turbine selection for wind farm layout using multi-objective evolutionary algorithms". Expert Syst. Appl., vol 41, no. 15, pp. 6585-6595, November 2014.

[15] S. Chowdhury, A. Mehmani, J. Zhang, and A. Messac, "Market suitability and performance tradeoffs offered by commercial wind turbines across differing wind regimes", Energ., vol. 9, no. 5, pp. 352383, May 2016.
[16] K. Martin, M. Schmidt, S. Shelton, and S. Stewart, "Site specific optimization of rotor/generator sizing of wind turbines", ASME Energy Sustainablility Conference., 2007, pp. 1123-1130.

[17] A. Bekele, and A. Ramayya, "Site specific design optimization of horizontal axis wind turbine based on minimum cost of energy for Adama I wind farm”, Int. J. Eng. Res. Tech., vol. 2, no. 7, pp. 862-870, July 2013.

[18] K. Helgason, "Selecting optimum location and type of wind turbines in Iceland", Master's Theses, Reykjavík University, Reykjavík, Iceland, 2012.

[19] G. Eke, and J. Onyewudiala, "Optimization of wind turbine blades using genetic algorithm", Global J. Res. Eng., vol. 10, no. 7, pp. 22-26, December 2010

[20] M. Jureczko, M. Pawlak, and A. Mezyk, "Optimisation of wind turbine blades", J. Mat. Process. Tech., vol, 167, no. 2, pp. 463-471, August 2005.

[21] F. Jowder, "Wind power analysis and site matching of wind turbine generators in Kingdom of Bahrain", Appl. Energ., vol. 86, no. 4, pp. 538-545, April 2009.

[22] M. El-Shimy, "Optimal site matching of wind turbine generator: Case study of the Gulf of Suez region in Egypt" Renew. Energ., vol. 35, no.8, pp. 1870-1878, August 2010.

[23] Y. Dong, J. Wang, H. Jiang, and X. Shi, "Intelligent optimized wind resource assessment and wind turbines selection in Huitengxile of Inner Mongolia, China", Appl. Energ., vol. 109, pp. 239-253, September 2013.

[24] R. Saaty, "The analytic hierarchy process - what it is and how it is used", Math. Modelling, vol. 9, no.3, pp. 161-176, May 1987.

[25] Z. Shirgholami, S. Zangeneh, and M. Bortolini, "Decision system to support the practitioners in the wind farm design: A case study for Iran mainland”, Sust. Energ. Tech. Assess., vol. 16, pp. 1-10, August 2016.

[26] V. Bagočius, E. Zavadskas, Z. Turskis, "Multi-person selection of the best wind turbine based on the multi-criteria integrated additive multiplicative utility function", J. Civil Eng. Manage., vol. 20, no. 4, pp. 590-599, July 2014

[27] A. Lee, M. Hung, H. Kang, and W. Pearn, "A wind turbine evaluation model under a multi-criteria decision making environment", Energ. Convers. Manage.,vol. 64, pp. 289-300, December 2012.

[28] M. Du, J. Yi, P. Mazidi, L. Cheng, and J. Guo, "A parameter selection method for wind turbine health management through SCADA data", Energ., 2017, vol. 10, no. 2, pp. 253-267, February 2017.

[29] S. Khan, and S. Rehman, "On the use of unified and-or fuzzy aggregation operator for multi-criteria decision making in wind farm design process using wind turbines in $500 \mathrm{~kW}-750 \mathrm{~kW}$ range", In Proceedings of the IEEE International Conference on Fuzzy Systems, Brisbane, Australia, pp. 1-6, June 2012.

[30] S. Khan, and S. Rehman, S, On the use of Werners fuzzy aggregation operator for multi-criteria decision making in wind farm design process using wind turbines in $1000 \mathrm{~kW}-1200 \mathrm{~kW}$ range. In Proceedings of the International Clean Energy Conference, Quebec, 2012, pp. 163-170, June 2012.

[31] S. Rehman, and S. Khan, "Fuzzy logic based multi-criteria wind turbine selection strategy - a case study of Qassim, Saudi Arabia. Energ., vol. 9, no. 11, pp. 872-898, October 2016.

[32] S. Gass, and T. Saaty, "The computational algorithm for the parametric objective function” Nav. Res. Log. vol. 2, no. 1, pp. 39-45, March 1955

[33] C. A. Coello-Coello. "A comprehensive survey of evolutionary-based multiobjective optimization techniques" Knowl. Inform. Syst., vol. 1, no. 3, pp. $269-308$, August 1999. 